\title{
POLÊMICAS SOBRE A LEGISLAÇÃO FEDERAL DE COTAS ÉTNICO-RACIAIS NO BRASIL
}

\author{
CONTROVERSIES ON THE FEDERAL LAWS OF \\ ETHNIC-RACIAL QUOTAS IN BRAZIL
}

Elói Martins Senhoras *

Data de recebimento: $22 / 02 / 2015$

Data da aprovação: 10/06/2015

\section{RESUMO}

A difusão das políticas e ações afirmativas de natureza étnico-racial por parte do Estado brasileiro tem trazido uma crescente discussão sobre o papel das cotas como instrumentos de focalização das políticas públicas que obedecem a uma lógica de discriminação positiva a fim de promoção de reparação e inclusão social de determinados grupos. O objetivo da pesquisa é trazer à luz de uma revisão bibliográfica e documental os diferentes debates polarizados de crítica e defesa da política de cotas étnico-raciais consubstanciadas no país. Com base nestas discussões, o artigo aborda a legislação de cotas étnico-raciais no Brasil consolidadas, tanto, pela Lei 12.711/2012, relacionada ao ingresso em instituições de ensino superior, quanto,

\footnotetext{
* Professor e pesquisador do Departamento de Relações Internacionais (DRI), do Programa de Mestrado em Geografia (PPG-GEO), do Programa de Mestrado em Sociedade e Fronteiras (PPG-SOF) e do Programa de Mestrado em Desenvolvimento Regional da Amazônia (PPG-DRA) da Universidade Federal de Roraima (UFRR). Graduado em Economia. Graduado em Política. Especialista pós-graduado em Administração - Gestão e Estratégia de Empresas. Especialista pós-graduado em Gestão Pública. Mestre em Relações Internacionais. Mestre em Geografia Geoeconomia e Geopolítica. Doutor em Ciências. Pós-Doutor em Ciências Jurídicas. Foi visiting scholar na Escola Nacional de Administração Pública (ENAP), no Instituto de Pesquisa Econômca Aplicada (IPEA), na University of Texas at Austin, na Universidad de Buenos Aires, na Facultad Latinoamericana de Ciencias Sociales, México e na National Defense University e visiting researcher na Escola de Administração Fazendária (ESAF), na Universidad de Belgrano (UB), na University of British Columbia e na University of California, Los Angeles.

E-mail: eloisenhoras@gmail.com
} 
pela Lei 12.990/2014 que regulamenta a reserva de vagas para afrodescendentes nos concursos de cargos públicos.

\section{PALAVRAS-CHAVE}

Ações afirmativas; cotas; discriminação positiva; políticas de focalização.

\section{ABSTRACT}

The widespread of affirmative policies and actions of ethnic and racial nature by the Brazilian State has brought a growing discussion about the role of quotas as instruments of targeting policies that obey a logic of positive discrimination in order to promote social repair and inclusion for certain groups. This research aims to bring into the light the different polarized debates of criticism and defense about the ethnic-racial quota policy embodied in the country through a bibliographical and documentary review. Based on these discussions, this paper focus on the legislation of ethnic and racial quotas in Brazil consolidated both by the Federal Law 12.711/2012 related to the access to institutions of higher education as well as the Federal Law 12.990/2014 that regulates the access of afro descendants in jobs in the Public Administration.

\section{KEYWORDS}

Affirmative action; quotas; positive discrimination; targeting policies. 


\section{INTRODUÇÃO}

As cotas são consideradas um dos mais relevantes instrumentos de discriminação positiva presentes na experiências internacional das ações afirmativas em favor de grupos vulneráveis, cuja justificativa de aplicação se fundamenta no objetivo de compensar ou reparar desigualdades materialmente construídas assincronicamente ao longo do tempo.

Justificadas pelas desigualdades existentes na participação de determinados grupos sociais na educação ou no mercado de trabalho, as cotas são consideradas como instrumentos temporários de políticas de focalização social, com baixo impacto orçamentário, relativa precisão e alta repercussão no curto prazo para promover a inclusão social

Sob o prisma da política étnico-racial construída a partir da Constituição Federal de 1988, as cotas se tornaram na estratégia maior para a promoção de ações afirmativas focalizadas a determinados grupos sociais, consolidando-se em um contexto de translação nos padrões das políticas públicas devido aos baixos custos orçamentários e a comprovada experiência internacional de décadas anteriores.

Conforme Fry (2006), surgiu um amplo consenso de que a política étnicoracial do Estado brasileiro tem mudado radicalmente desde a Constituição Federal de 1988, passando pela transformação de uma clássica política de laissez-faire, alicerçada no princípio da igualdade desde a promulgação da República, em direção a inovativas políticas de discriminação positiva por meio de ações afirmativas como os sistemas de cotas, a partir da década de 2000.

O ano de 2001 foi exemplar em função da III Conferência Mundial de Combate ao Racismo, Discriminação Racial, Xenofobia e Intolerância Correlata, quando a delegação oficial brasileira se comprometeu a lutar contra a discriminação e propôs a adoção de ações afirmativas, momento este que forneceu impulso nacional ao surgimento de políticas e ações afirmativas por parte do Estado (SOUSA e PORTES, 2011).

No bojo das transformações da política étnico-racial no Brasil, o surgimento de ações afirmativas de natureza estatal em diferentes entes federativos, principalmente por meio de legislações sobre sistemas de cotas em vestibulares e em concursos públicos, manifestou o contexto de maturação das políticas públicas com focalização a determinados grupos em condição vulnerável.

Fruto de um esforço legiferante originado no Poder Executivo, a aprovação dos sistemas de cotas para ingresso em Instituições Federais de Ensino Superior (Lei $n^{\circ}$ 12.711/2012) e para ingresso em cargos públicos na Administração Pública 
Federal (Lei 12.990/2014) trouxe significativa contribuição para fervorosos debates polarizados pelos efeitos extremados de percepções de defesa ou crítica.

Com base nestas discussões previamente apresentadas, o presente artigo está estruturado em duas seções, incluídas a presente introdução e a conclusão, as quais têm como objetivo geral dissertar sobre os debates e polarizações existentes a respeito da legislação brasileira de cotas étnico-raciais na educação e em cargos públicos federais.

Na primeira seção, "Lei de cotas nos vestibulares de instituições federais de ensino superior", o artigo finda apresentar os marcos evolutivos dos sistemas de cota na educação no Brasil à luz dos debates e doutrinas jurídicas apresentadas a respeito da implementação desta ação afirmativa.

$\mathrm{Na}$ segunda seção, "Lei das cotas em concursos da Administração Pública Federal", o texto apresenta os prós e contras do sistema de cotas para negros com base em uma análise da constitucionalidade, eficiência e dos interesses políticos envolvidos da Lei 12.990/2014.

Por fim, últimas considerações são trazidas à guisa de conclusão a fim de sintetizar os principais debates abordados no texto sobre as reservas de vagas, bem como, apontar os desafios existentes em um contexto de clara polarização social entre defensores e críticos aos sistemas de cotas étnico-raciais.

\section{LEI DE COTAS NOS VESTIBULARES DE INSTITUIÇÕES FEDERAIS DE ENSINO SUPERIOR}

O governo Brasileiro sancionou, no ano de 2012, uma das leis de ação afirmativa, mais abrangentes, do hemisfério ocidental, exigindo que as universidades públicas reservem, ao menos, metade de suas vagas para alunos das escolas públicas, o que refletirá no aumento do número de estudantes universitários de menor renda e de ascendência africana e indígena por todo o país, conforme as especificidades de cada estado.

A entrada em vigor deste novo marco normativo, Lei $n^{\circ} 12.711 / 2012$, conhecida como lei das cotas, configura-se como ponto de inflexão sobre o entendimento da reserva de vagas no sistema educacional brasileiro devido, tanto, à universalização dessa política educacional em todo o território nacional, quanto, à incorporação de inovações pragmáticas, que caracterizam o sistema de cotas não apenas no aspecto étnico-racial, mas também social, atendendo à polarização de debates existentes previamente na década de 2000. 
De um lado, há um grupo de estudiosos, doutrinadores e juristas que compreende a legítima importância executiva de entidades públicas, privadas, ou mesmo de órgãos dotados de competência jurisdicional na implementação de instrumentos políticos, como as cotas, para reduzir desigualdades de oportunidades e universalizar o acesso ao ensino superior.

O apoio e promoção de determinados grupos socialmente fragilizados, quando identificados por categorias de gênero, idade, necessidades especiais, etnia e raça trata-se de um instrumento político relevante para a materialização do princípio da igualdade, o qual já fora incorporado décadas atrás em outros sistemas jurídicos e tem sido conhecido pelos conceitos de ação afirmativa, na literatura anglo-saxã, ou, pelos termos de discriminação positiva e ação positiva, na literatura européia (GOMES, 2001).

Conforme Mello (2003), no contexto da ação afirmativa, há fundamentos para o entendimento de que o princípio da isonomia não é absoluto, mas antes passa por relativizações que permitem a autorização de distinção entre pessoas quando houver justificativa razoável e objetiva, em especial, quando se procura promover o atendimento ao princípio da igualdade e aos direitos e garantias constitucionais.

De outro lado, estão presentes posições e argumentos contrários ao instituto que ficou popularizado no Brasil pelo termo de ação afirmativa nas universidades, baseando-se no princípio constitucional da isonomia, uma vez que as críticas convergem no sentido de denunciar um impacto negativo das cotas, ao procurar criar artificialmente uma divisão classificatória na sociedade por raças, em um país que na realidade é multiétnico, o que acaba por muitas vezes realçando o racismo (FRY, 2009; MAGGIE, 2008).

Em primeiro lugar, a vertente crítica às cotas étnico-raciais toma como referência, não apenas, um discurso tradicionalista sobre o mito da democracia racial, no qual se mostra a artificialidade de se categorizar raças em uma sociedade amplamente miscigenada, mas também, um questionamento à quebra do princípio constitucional da isonomia, uma vez que as cotas seriam medidas paliativas, que propõem amenizar desvantagens sociais e compensar certas deficiências.

Em segundo lugar, o debate crítico introduz um novo discurso em que o problema nacional relaciona-se às classes sociais, entre pobres e ricos, motivo pelo qual, tratar desigualmente os desiguais deveria levar em consideração uma política social que privilegiasse os mais pobres, onde estão concentrados negros, pardos, índios e uma pluralidade de outras identificações em situação vulnerável.

Frente a este contexto de polarizações, a normatização de cotas étnico-ra- 
ciais e sociais em Universidades e Institutos Federais, claramente, surge no país em razão da exclusão social ser identificada como um fato jurídico de relevância social, no qual determinadas Instituições de Ensino Superior (IES) já haviam manifestado importância fática jurígena, por meio de uma série de valores e princípios afirmativos que repercutiram no surgimento de políticas de cotas.

Em uma embrionária influência, observa-se que a evolução da trajetória fática de ações afirmativas tem uma primeira contribuição jurígena em 1967, com a Convenção Internacional Sobre a Eliminação de todas as Formas de Discriminação Racial da Organização das Nações Unidas, reflexiva à luta pelos direitos civis nos Estados Unidos na década de 1960, porém, com pouco impacto no Brasil.

A materialização de ações afirmativas no Brasil, com uma implicação no ensino superior, somente, surge na década de 2000, com as primeiras experiências no contexto acadêmico de promoção do sistema de cotas, respectivamente, em nível estadual, com as políticas da Universidade do Estado do Rio de Janeiro (UERJ) e da Universidade Estadual do Norte Fluminense (UENF), e, em nível federal, com a iniciativa da Universidade de Brasília (UnB) em 2001.

Diferentemente dos Estados Unidas, onde as cotas quantitativas são ilegais para ingresso em instituições de ensino superior, embora estas adotem ações afirmativas qualitativas para recrutar os alunos desde os anos 1970, no Brasil, o modelo das políticas de ação afirmativas se difundiu amplamente em uma série de universidades federais e estaduais com base na reserva quantitativa de vagas, o que repercutiu na formação de polêmicas.

O recente debate em torno das Políticas de Ações Afirmativas (PAAF) com reservas de vagas para grupos sociais específicos nas universidades públicas brasileiras nunca foi tão representativo no Brasil. A implantação da política de acesso no ensino superior brasileiro, pelo sistema de reservas de vagas, tornou-se alvo constante de amplas mobilizações e discussões entre a comunidade jurídica, acadêmica, escolar e outros setores da sociedade ligados direta e indiretamente à questão em pauta. (GARCEZ, 2013, p. 216).

A difusão das experiências anteriores implicou na adoção de sistemas cotas em outras instituições de ensino superior no Brasil, o que resultou em uma enxurrada de pedidos de mandados de segurança, por parte de candidatos que se sentiram prejudicados, motivo pelo qual os poderes, legislativo, judiciário e executivo, foram pressionados a se pronunciarem posteriormente, tendo destaque o ano de 2012.

A despeito das respostas ao longo da década de 2000, como o projeto de lei 
3.627/2004, é somente no ano de 2012 que a discussão sobre o sistema de reserva de vagas se materializa, inicialmente, com a jurisprudência criada por decisão do STF, no mês de abril, e, posteriormente, com o surgimento da lei das cotas, pronunciado pelo poder legislativo em agosto, e, sua regulamentação em outubro, pelo poder executivo.

A nova política de cotas para ingresso em instituições federais técnicas e de ensino superior incorporou as críticas de que os problemas de inclusão não são exclusivamente étnico-raciais, mas sim socioeconômicos, motivo pelo qual a reserva de no mínimo $50 \%$ das vagas deve ser direcionada a estudantes que tenham cursado todo o ensino médio em escolas da rede pública.

\section{Quadro 1 - Marcos para a ação afirmativa no ensino superior brasileiro}

\begin{tabular}{|c|c|}
\hline 1967 & $\begin{array}{l}\text { Na Convenção Internacional Sobre a Eliminação de todas as Formas de } \\
\text { Discriminação Racial da Organização das Nações Unidas, o Brasil, como } \\
\text { Estado-signatário, comprometeu-se a aplicar as ações afirmativas como } \\
\text { forma de promoção da igualdade para inclusão de grupos étnicos historica- } \\
\text { mente excluídos no processo de desenvolvimento social. }\end{array}$ \\
\hline 2004 & $\begin{array}{l}\text { O projeto de lei } 3.627 / 2004 \text { é considerado como o fio condutor para a fo- } \\
\text { mentação da nova lei de cotas, pois trouxe na agenda de discussões do } \\
\text { Congresso Nacional a inserção da temática de criação de um sistema es- } \\
\text { pecial de reserva de vagas para alunos provenientes de escolas públicas, } \\
\text { em especial para os grupos negros e indígenas. }\end{array}$ \\
\hline \multirow{3}{*}{2012} & $\begin{array}{l}\text { O Supremo Tribunal Federal (STF), em } 26 \text { de abril de } 2012 \text {, considerou } \\
\text { constitucional a política de cotas étnico-raciais para a seleção de estu- } \\
\text { dantes da Universidade de Brasília (UnB), que reservava } 20 \% \text { de seus } \\
\text { lugares para estudantes negros e mestiços, em julgamento unânime dos } \\
\text { ministros em resposta à Arguição de Descumprimento de Preceito Funda- } \\
\text { mental } n^{\circ} 186 \text {. }\end{array}$ \\
\hline & $\begin{array}{l}\text { A lei } n^{\circ} 12.711 \text {, de } 29 \text { de agosto de } 2012 \text {, torna-se um marco divisor de } \\
\text { águas das políticas afirmativas voltadas ao processo seletivo para o acesso } \\
\text { ao ensino superior público no país, haja vista que criou desde então um re- } \\
\text { ferencial com efeitos em cascata em instituições não apenas federais, mas } \\
\text { também estaduais e municipais. }\end{array}$ \\
\hline & $\begin{array}{l}\text { O decreto } n^{\circ} 7.824 \text {, de } 11 \text { de outubro de } 2012 \text {, trouxe uma rápida regula- } \\
\text { mentação da lei das cotas pelo poder executivo federal, ao dispor sobre } \\
\text { o funcionamento do sistema de reserva de vagas, com base em critérios } \\
\text { étnico-racial-sociais em institutos e universidades federais e em instituições } \\
\text { federais de ensino técnico de nível médio. }\end{array}$ \\
\hline
\end{tabular}

Fonte: Elaboração própria. Baseada em Garcez (2013) e STF (2012) 
A positiva hibridez normativa da Lei 12.711/2012 demonstra uma promoção socioeconômica genérica, que reserva uma cota mínima de 50\% das vagas nas IFES, a estudantes que estudaram em escolas da rede pública vis-à-vis a uma promoção étnico-racial especifica com a distribuição proporcional das vagas das cotas entre negros, pardos e indígenas, conforme as características populacionais de cada estado.

A Lei 12.711/2012, popularmente conhecida como lei de cotas, trata-se de um instrumento de justiça social e combate ao racismo, que deve gradativamente ampliar a o número de estudantes negros, pardos e indígenas nas instituições federais de ensino superior, de maneira proporcional à composição da população total em cada estado, conforme os dados do Instituto Brasileiro de Geografia e Estatística (IBGE).

A trajetória fática da desigualdade social, manifestada por questões étnicoraciais, demonstra que a aprovação da Lei 12.711/2012 acontece após o desenvolvimento de um amplo debate encadeado desde o início da década de 2000, motivo pelo qual às vésperas da implantação do novo marco legal, já existiam 80 IES que adotavam algum tipo de política de inclusão, baseando-se em critérios étnico-raciais ou sociais.

Destarte, observa-se que a Lei 12.711 surge no ano de 2012, como reflexo de lutas sociais que em determinado momento se manifestaram em polarizações e em contestações judiciais que chegaram ao Supremo Tribunal Federal (STF), relacionadas às políticas afirmativas pré-existentes, de maneira, concentrada nas regiões sul, sudeste e nordeste do país, em 80 universidades federais, estaduais e municipais.

\section{Gráfico 1 - Políticas de cotas em IES no Brasil}

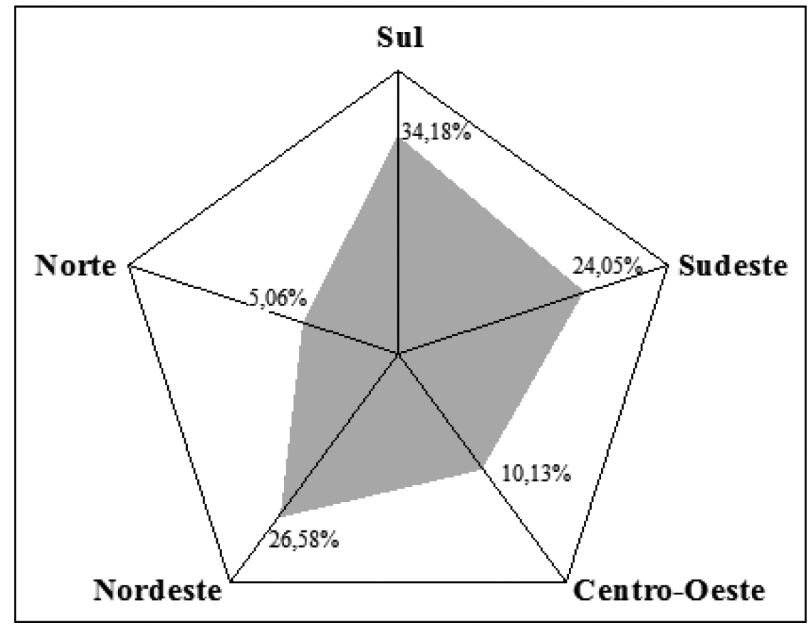

Fonte: Elaboração própria. Banco de dados: UERJ (2013) 
Com validade de dez anos após a entrada em vigor no ano de 2012, e, posterior revisão pelo poder executivo, a lei das cotas trata-se de um instrumento conjuntural que busca diminuir problemas sociais historicamente consolidados no Brasil por meio da estruturação de um coeficiente mínimo de 50\% das vagas para ingresso em IFES a estudantes que tenham cursado todo o ensino médio em escolas da rede pública, de maneira a levar em consideração critérios de renda e étnico-raciais, conforme identificado na figura 1 .

A Lei $\mathrm{n}^{\mathrm{o}} 12.711 / 2012$, sancionada em agosto deste ano, garante a reserva de $50 \%$ das matrículas por curso e turno nas 59 universidades federais e 38 institutos federais de educação, ciência e tecnologia a alunos oriundos integralmente do ensino médio público, em cursos regulares ou da educação de jovens e adultos. Os demais $50 \%$ das vagas permanecem para ampla concorrência. [...] Em 2013 terão de ser reservadas, pelo menos, 12,5\% do número de vagas ofertadas atualmente - o que equivale a $25 \%$ do total que será reservado para ingresso por meio de cotas. A implantação das cotas ocorrerá de forma progressiva ao longo dos próximos quatro anos, até chegar à metade da oferta total do ensino público superior federal. [...] O acompanhamento ficará a cargo de um comitê composto por representantes do Ministério da Educação, da Secretaria de Políticas de Promoção da Igualdade Racial (Seppir) e da Fundação Nacional do Índio (Funai), com a participação de representantes de outros órgãos e entidades e da sociedade civil (MEC, 2013, s.n.).

Na prática, a lei de cotas cria um sistema de reserva de vagas nas instituições federais de ensino superior e nos institutos técnicos que dá uma nova função social da universidade pública quanto à pluralidade e acesso democrático, ao ter como objetivo a atenuação do quadro de desigualdade em que os estudantes da rede de ensino público estão inseridos em relação àqueles da rede privada.

A lei obriga as universidades públicas a designarem suas vagas de acordo com a formação racial de cada um dos 26 estados brasileiras e da capital, Brasília, o que vai repercutir em pelo menos quatro contextos de composição estudantil no ensino superior distintos no país.

Em primeiro lugar, com a reserva de cotas a estudantes que cursaram todo o ensino médio em escolas públicas, espera-se em boa parte dos estados brasileiros em que há elevada uma formação sócio-histórica baseada na miscigenação, a incorporação de um amplo contingente de estudantes das classes sociais de renda baixa, cujo perfil étnico-racial é amplo e não restrito a índios e negros. 
Em segundo lugar, em função das especificidades da composição humana em determinadas macro-regiões e estados, o sistema de cotas deve conduzir a três situações de especificidade, seja, em razão, da alta ou baixa concentração de determinadas composições étnico raciais em condição de vulnerabilidade:

a) Nos Estados com um grande número de negros ou populações mestiças, este perfil humano poderia conduzir a um aumento de alunos identificados como negros nas instituições de ensino superior, a título de exemplo dos estados do Nordeste, como na Bahia.

b) Naqueles estados da região Norte e Centro-Oeste do país, em função do número de indígenas na população total, é de se esperar a incorporação destes grupos populacionais indígenas nas instituições de ensino superior, em especial, no Acre e Roraima.

c) Naqueles estados com maior homogeneidade étnico-racial de origem européia, como é o caso dos estados da região Sul do país, é de se esperar que as cotas incorporarão um baixo coeficiente de negros e indígenas, já que os novos estudantes selecionados serão brancos de uma faixa de renda menor.

Com base nestas discussões, conclui-se que a lei das cotas cria repercussões no mecanismo de acesso ao ensino superior público federal, e, por conseguinte, um efeito cascata sobre instituições de ensino superior, privadas, e, públicas, estaduais e municipais, na inclusão e acessibilidade a diferentes grupos sociais, baseando-se em um modelo, reconhecido como legítimo e constitucional à luz das decisões do STF, que prioriza a promoção do princípio da igualdade em relação à temporal quebra do princípio da isonomia ao longo dos próximos dez anos.

\section{LEI DAS COTAS EM CONCURSOS DA ADMINISTRAÇÃO PÚBLICA FEDERAL}

A reserva de vagas para afrodescendentes trata-se de uma ação afirmativa instituída pelo Poder Executivo por meio da Lei 12.990/2014 para concursos da Administração Pública Federal, incluídas autarquias, fundações públicas, empresas públicas e sociedades de economia mista controladas pela União, sem necessária extensão de cotas para concursos, seja nos Poderes Legislativo e Judiciário, seja nos entes subnacionais de estados e municípios.

O surgimento da Lei Federal 12.990/2014 não aconteceu por acaso, mas antes é o resultado de benchmarking em exemplos de sistemas de cotas raciais em 
concursos públicos implementados, tanto, no plano internacional, como nos casos da Índia, na década de 1940, e, dos Estados Unidos, na década de 1960, quanto, no plano nacional, em estados como Paraná, Mato Grosso do Sul, Rio de Janeiro e Rio Grande do Sul, na década de 2000.

Oriunda de uma incremental agenda política de defesa de grupos minoritários e em condição vulnerável aberta pelo governo de Fernando Henrique Cardoso e que foi crescentemente sendo ampliada institucionalmente nos governos de Luiz Inácio Lula da Silva e Dilma Rousseff, a Lei Federal 12.990/2014 é o fruto de uma evolução nas discussões de ação afirmativa do aparelho do Estado com os movimentos sociais, em conformidade com os receituários de organismos multilaterais como o Banco Mundial para a focalização de políticas sociais compensatórias ${ }^{1}$.

Conforme Senhoras (2005), enquanto, internacionalmente as estratégias de discriminação positiva presentes em ações afirmativas estão sendo retaliadas por outras políticas sociais focalizadas de natureza neoliberal, como é o caso estadunidense, no Brasil, elas foram propostas inicialmente pelos setores que mais apoiavam o neoliberalismo, refletindo não necessariamente a convergência de uma luta dos negros brasileiros à cidadania, mas antes, refletindo a incorporação de uma tendência internacional retardatária que passou por releituras endógenas.

Fundamentado pela noção de discriminação positiva de ações afirmativas para afrodescendentes, com a suposta ideia de combater, minimizar ou compensar os efeitos negativos da escravidão e do descaso estatal com os afrodescendentes, o Projeto de Lei 6.738/2013 foi apresentado em caráter de urgência pelo Governo Federal ao Congresso Nacional para a reserva de $20 \%$ das vagas dos cargos da administração pública federal para negros, resultando na Lei 12.990/2014 (SILVA e SILVA, 2014).

A Lei Federal 12.990/2014 que disciplina temporalmente a política de cotas raciais em concursos públicos federais com uma vigência de dez anos, entre 2014 e 2024, apresenta sua fundamentação de discriminação positiva a fim de promover a igualdade material em um tripé de antecedentes que é identificado pelas dimensões fática, axiológica e normativa.

\footnotetext{
${ }^{1}$ A difusão internacional de um padrão de política pública focalizada a partir da década de 1990 é o resultado da implementação de um receituário neoliberal sugerido por organismos multilaterais a fim de concentrar esforços orçamentários em populações alvo, diferentemente do que ocorreu em décadas anteriores desde a II Guerra Mundial, quando se consolidou o padrão de política pública universalizante por meio de um receituário keynesiano (SENHORAS, 2003).
} 
$\mathrm{Na}$ dimensão fática, a política de cotas raciais em concursos públicos federais assenta-se na difusão de debates fora e dentro do Estado sobre ações afirmativas e discriminações positivas em razão da crescente organização de movimentos sociais que buscavam, tanto, conquistar novos direitos, quanto, regulamentar direitos e garantias previstos na Constituição Federal de 1988.

$\mathrm{Na}$ dimensão axiológica, com a Constituição Federal de 1988, os conceitos de vulnerabilidade (gênero) e hipossuficiência (espécie) forneceram fundamentação para a conformação das primeiras políticas de focalização a determinados atores e grupos sociais, repercutindo assim em uma crescente e ampla difusão do princípio da proteção para alicerçar direitos e garantias de minorias e grupos vulneráveis.

$\mathrm{Na}$ dimensão normativa, a política de cotas em concursos públicas tem raiz nos marcos normativos de inclusão, garantismo jurídico e reparação a danos, presentes na Lei 7.853/1989, conhecida como Política Nacional para a Integração da Pessoa Portadora de Deficiência e regulamentada pelo Decreto 3.298/1999; na Lei 9.504/1997 que estabeleceu ação afirmativa em favor do sexo feminino por meio de cota eleitoral, bem como na Lei n. 12.288/2010, que estabeleceu o Estatuto da Igualdade Racial, e, na Lei 12.711/2012, intitulada Lei de Cotas para o Ensino Superior.

Com base nesta visão tridimensional do Direito sobre a conformação da Lei Federal 12.990/2014, observa-se que a despeito das polêmicas e polarizações existentes nos debates teóricos e doutrinários sobre o assunto, ela é claramente oriunda de uma maturação de fatos e ações políticas que gradativamente foram se consolidando após a Constituição Federal de 1988, a partir de um perfil de política pública de focalização para um público alvo de afrodescendentes e com conteúdo de discriminação positiva reparatória.

As principais características da discriminação positiva do sistema de cotas para afrodescendentes em concursos federais de cargos públicos, de acordo com a Lei Federal 12.990/2014, são resumidas em um percentual de 20\% das vagas, com critérios de condicionalidade previstos quanto: a) número mínimo de vagas oferecidas em concurso para aplicação de cota; b) fracionamento das vagas; c) auto declaração de negro ou pardo; e, d) dupla forma de ingresso, tanto, por reserva de cota, quanto, por ampla concorrência. 


\section{Quadro 1 - Destaques na Lei 12.990/2014}

Art. $1^{\circ}$ - Ficam reservadas aos negros $20 \%$ (vinte por centro) das vagas oferecidas nos concursos públicos para provimento de cargos efetivos e empregos públicos no âmbito da administração pública federal, das autarquias, das fundações públicas, das empresas públicas e das sociedades de economia mista controladas pela União, na forma desta Lei.

Parágrafo $1^{\circ}$ - A reserva de vagas será aplicada sempre que o número de vagas oferecidas no concurso público for igual ou superior a 3 (três).

Parágrafo $2^{\circ}$ - Na hipótese de quantitativo fracionado para o número de vagas reservadas a candidatos negros, esse será aumentado para o primeiro número inteiro subsequente, em caso de fração igual ou maior que 0,5 (cinco décimos), ou diminuído para número inteiro imediatamente inferior, em caso de fração menor que 0,5 (cinco décimos).

\section{(..)}

Art. $2^{\circ}$ - Poderão concorrer às vagas reservadas a candidatos negros aqueles que se autodeclararem pretos ou pardos no ato da inscrição no concurso público, conforme o quesito cor ou raça utilizado pela Fundação Instituto Brasileiro de Geografia e Estatística - IBGE.

Parágrafo único - Na hipótese de constatação de declaração falsa, o candidato será eliminado do concurso e, se houver sido nomeado, ficará sujeito à anulação da sua admissão ao serviço ou emprego público, após procedimento administrativo em que Ihe sejam assegurados o contraditório e a ampla defesa, sem prejuízo de outras sanções cabíveis.

Art. $3^{\circ}$ - Os candidatos negros concorrerão concomitantemente às vagas reservadas e às vagas destinadas à ampla concorrência, de acordo com a sua classificação no concurso.

Parágrafo $1^{\circ}$ - Os candidatos negros aprovados dentro do número de vagas oferecido para ampla concorrência não serão computados para efeito do preenchimento das vagas reservadas.

Parágrafo $2^{\circ}$ - Em caso de desistência de candidato negro aprovado em vaga reservada, a vaga será preenchida pelo candidato negro posteriormente classificado.

Fonte: Brasil (2014)

Enquanto instrumento especial e temporário de focalização da política pública, a discriminação positiva da cota racial em concursos públicos, implementada pelo Poder Executivo brasileiro, caracteriza-se como uma estratégia de compensação 
para fortalecer o negro, pois ao romper a igualdade formal na norma tem por objetivo promover a igualdade material por meio de oportunidades que diminuam desigualdades historicamente acumuladas pela discriminação e marginalização (GLUTZ, 2010).

A discriminação positiva presente na Lei Federal 12.990/2014 introduz o tratamentodesigualdos formalmenteiguaistomandocomoreferência,tanto,aexperiência nacional da reserva de vagas de cargos públicos para deficientes físicos determinada pela Constituição Brasileira de 1988, quanto, a experiência internacional difundida em diferentes legislações desde a promoção de ações afirmativas nos Estados Unidos na década de 1960, por meio de cotas para grupos excluídos e estigmatizados em vagas escolares e em listas de candidatos a cargos políticos.

Caracterizada como um dos últimos instrumentos de discriminação positiva na focalização de políticas para a população negra, a Lei Federal 12.990/2014, o fazer parte de uma trajetória evolutiva de ações afirmativas estatais para afrodescendentes no Brasil e a própria Lei Federal 12.990/2014, acabou não passando desapercebida da opinião pública, mas justamente ao contrário, suscitando polarizações contrárias e a favor que se manifestaram, também, nos debates entre os especialistas e doutrinadores sobre o assunto.

Por um lado, existe uma positiva interpretação da aprovação da Lei 12.990/2014 que estabeleceu as cotas raciais para negros e pardos para ingresso na Administração Pública Federal, uma vez que ela seria potencialmente um instrumento de justiça corretiva adequado à promoção da igualdade por meio de um perfil de política de targeting ou focalização que impacta diretamente na população alvo diferentemente de tradicionais políticas públicas universais de natureza social.

A efetividade da focalização de uma política pública exclusiva para afrodescendentes, conforme prevista na Lei das Cotas em Concursos Públicos, é demonstrada pela sua racionalização como política social, ao proporcionar eficiência pontual, justamente por propiciar uma ação reparatória, ao atingir uma população com problemas consolidados assincronicamente ao longo da formação histórica do país (SILVA e SILVA, 2014).

Sob a ótica doutrinária, a recepção positiva da Lei 12.990/2014 acontece uma vez que a Constituição Federal de 1988, não só não vedou a adoção de medidas de discriminação positiva, mas, antes, a favoreceu, pois, o legislador constituinte definiu os objetivos fundamentais da República Federativa do Brasil no artigo $3^{\circ}$ com verbos que evocam ação, como construir, erradicar, reduzir, promover, bem como introduziu 
no artigo 37, VIII, o caso da discriminação positiva de portadores de deficiência.

O legislador constituinte trouxe na Carta Magna o entendimento de que existem temas de aplicação da regra da desigualação para igualar, como o caso das cotas raciais em concursos públicos, em que incidem as ações afirmativas reparatórias com uma natureza de discriminação positiva, já que o igual tratamento formal pela lei, para ser legítimo, pressupõe uma igualdade fática preexistente (TRINDADE, 1998; ROCHA, 1996).

De acordo com Silva (2011), a insistência na questão da superação do paradoxo da igualdade formal versus igualdade material se manifesta com crescente importância, uma vez que esta é uma discussão contemporânea em que se registra plena compatibilidade das políticas de ação afirmativa e de cotas para negros implantadas pelo Estado brasileiro com o ordenamento jurídico internacional, justamente porque o ponto central da discussão sobre o princípio da igualdade no Direito Internacional Comparado deixa de ser a isonomia formal de direitos e passa a ser a isonomia material do direito à igualdade de oportunidades.

Por outro lado, a Lei 12.990/2014 é questionada por afetar o princípio constitucional da igualdade, uma vez que a justiça corretiva da política de ação afirmativa ao procurar melhorar a condição de um grupo social o faz de maneira ineficiente, afetando negativamente a condição de outros grupos sociais no mesmo concurso público por meio de uma quebra da igualdade formal das normas que se estende a todos, sem distinção ou privilégio (QUINTÃO, 2014).

A Lei das Cotas é caracterizada não apenas como inconstitucional por afetar o princípio da igualdade no Estado Democrático de Direito, mas também ineficiente sob a ótica das políticas públicas, ao gerar um padrão de política seletiva e autoritária que melhora o bem-estar social de determinados atores, com aumento de eficiência parcial, embora, prejudicando o bem estar social de outros atores sociais, com efeitos na diminuição da eficiência geral.

Sob a ótica doutrinária ${ }^{2}$, os questionamentos da discriminação positiva da Lei 12.990/2014 indicam que ela impacta negativamente, tanto, nos interesses públicos primários, ao romper com o princípio da igualdade, quanto, nos interesses

\footnotetext{
2 Segundo uma corrente moderada de doutrinadores que dissertam sobre os sistemas de cotas raciais, a defesa ou ataque às políticas de discriminação positiva varia conforme a própria natureza do processo de ação afirmativa. De um lado, existe plausível defesa de cotas raciais para ingresso na Educação Superior durante um lapso temporal, quando se objetiva preparar estudantes em condição vulnerável para o mercado de trabalho, sendo o sucesso profissional uma condição ex post conquistada com base no mérito de cada estudante. De outro lado, existe crítica à cotas raciais para o ingresso na Administração Pública, pois estas pervertem o próprio sistema de mérito, tornando-se o sucesso profissional em uma condição ex ante que é determinada pelo perfil racial.
} 
públicos secundários, ao se desvencilhar do princípio da meritocracia que foi fundamental na evolução da Administração Pública Brasileira de um padrão patrimonialista em direção a um padrão burocrático que recentemente se converte em um padrão gerencial.

Por um lado, o questionamento sobre a inconstitucionalidade da Lei Federal 12.990/2014 surge lastreada pelo argumento de que ela afeta inúmeros dispositivos constitucionais, com destaque aos princípios da igualdade, já que a Constituição Federal de 1988 declara que todos são iguais, sem distinção de cor, raça, religião, não havendo espaço para um tratamento diferenciado entre negros e brancos no ordenamento jurídico brasileiro (BONADIMAN, 2013).

Por outro lado, também, cabe destacar a negação do princípio da meritocracia na Administração Pública, tendo em vista que a seleção de um candidato deixa de se basear na escolha dos mais aptos, passando a funcionar em função de cotas raciais que distorcem o fundamento do mérito no sistema, com significativo impacto de retrocesso no serviço público, voltando os cargos públicos a serem tratados como prebenda ou benesse do Estado à determinada pessoa, tal como na era do patrimonialismo (BARBOSA, 2014).

Embasando-se nos debates polarizados a favor e contra a Lei Federal 12.990, é observável que a condição paradoxal da Lei Federal 12.990/2014 reside no próprio instrumento das cotas, a qual propõe combater os efeitos da discriminação por meio de uma discriminação positiva, embora, gerando impactos negativos sobre inúmeros princípios constitucionais, com destaque à igualdade e à meritocracia, o que demonstrando que a sua evolução normativa no Brasil é fruto claro de um arranjo político e não de uma convergência teórica ou doutrinária.

Conclui-se que em um contexto polêmico de polarizações doutrinárias em relação à discriminação positiva do sistema de cotas em concursos para provimento a cargos públicos, a Lei Federal 12.990/2014 se consolida no Brasil em conformidade à tendência internacional, permeada pela falta de convergência nos debates nacionais e por contradições, já que não incorpora outros grupos étnico-raciais em condição vulnerável, mas que se materializa sob a liderança política da mão protetora do Estado na Era dos Direitos Humanos.

\section{ÚLTIMAS CONSIDERAÇÕES}

A legislação federal sobre cotas étnico-raciais no Brasil tem implicações que vão muito além da educação superior ou da carreira de servidores públicos, uma vez 
que implica em um projeto radicalmente novo de nação, no qual há uma mudança radical do estatuto jurídico republicano, baseado no princípio da igualdade, já que a raça e a discriminação deixam de ser entendidos como deletérios, mas antes passam a ser estimulados por políticas públicas focalizadas sob o prisma da discriminação positiva das ações afirmativas.

As leis que construíram os atuais sistemas de cotas na educação e em cargos públicos trazem consigo distintos bônus e ônus quanto ao projeto de nação e aos interesses públicos primário e secundário, cindindo a população e especialistas em um processo de polarização a favor ou contra a existência da reserva de vagas que vem até os dias atuais, mesmo após deliberação judicial de constitucionalidade das cotas.

Por um lado, surgiu um claro efeito halo entre os defensores das cotas étnico-raciais, caracterizado por uma subjetiva percepção que sobrevaloriza o potencial de eficiência do sistema de cotas na redução das desigualdades com base apenas na avaliação positiva das premissas primárias que fundamentam o sistema.

Os simpatizantes do sistema de cotas étnico-raciais apresentam, normalmente, um discurso focalizado na relevância deste instrumento de ação afirmativa devido à discriminação positiva nela prevista que repara ou compensa a inexistência de uma igualdade material nas populações alvo das cotas.

A discriminação positiva das cotas étnico-raciais passa a ser valorizada neste debate em função da sua natureza como ação afirmativa reparatória que atenua as desigualdades materiais e que proporciona a inclusão a cidadãos em situação dispare ou de marginalização social.

Os conceitos de raça e etnia presentes na defesa do sistema de cotas traz consigo a noção de que a discriminação positiva da ação afirmativa não acontece em razão de uma matriz biológica, mas, antes, em função de uma construção social que apresenta características estruturais que foram cristalizadas ao longo do processo histórico, as quais hodiernamente passam por reparações quanto aos efeitos negativos produzidos sobre determinados grupos sociais.

A ação afirmativa reparatória dos sistemas de cotas étnico-raciais é justificada por esta vertente de defensores a fim de criar oportunidades educacionais ou no mercado de trabalho para romper o ciclo vicioso da desigualdade assincronicamente enfrentada por diferentes gerações dos grupos sociais que foram afetadas negativamente ao longo dos processos históricos.

Por outro lado, surgiu a identificação de um efeito horn entre os críticos dos sistemas de cotas que é materializado por uma subvalorização quanto ao potencial de eficiência das cotas na resolução de problemas em relação à percepção inicial trazida 
pelos fundamentos críticos de teorização e lógica.

Os debates críticos aos sistemas de cotas no Brasil apresentam um viés de discussão que acaba migrando dos temas étnico-raciais em direção a um núcleo duro de problemas que estão diretamente ligados à constitucionalidade e à eficiência da discriminação positiva presente nestas políticas de ação afirmativa.

Conforme análise apresentada no artigo é possível compreender que o problema da implantação de qualquer sistema de cotas étnico-raciais no Brasil reside nos critérios de definição daqueles que têm direito e dos que não têm direitos, justamente em uma sociedade construída ao longo do século XX, na qual os indivíduos podiam transitar entre marcas ou até mesmo não se pensar a partir delas.

A despeito do mito da democracia racial brasileira ter sido claramente desconstruído ao longo do século XX, fica evidente que a definição rígida das cotas étnico-raciais incorre em um processo de reconstrução artificial de noções étnicas e raciais que são claramente fluidas em uma sociedade com alto grau de miscigenação, marcada por distintos padrões culturais.

Dado que em um sistema de cotas se faz necessária uma clara definição de critérios rígidos de classificação entre os indivíduos, torna-se evidente que qualquer comissão responsável por uma peritagem étnico-racial para se evitar fraudes acaba incorrendo em uma situação de subjetivismo já que a única convergência existente é que todos pertencem à raça humana sob os prismas cultural e biológico.

Ao se tomar como referência as polarizações dos debates entre críticos e defensores das cotas étnico-raciais no ensino superior e em cargos públicos federais, observa-se como ponto de convergência o entendimento de que as cotas étnicoraciais forçam um processo de identificação dos candidatos às vagas reservadas que no longo prazo pode gerar uma crescente étnico-racialização social em uma sociedade caracterizada pela miscigenação.

Conclui-se que a despeito das distintas posições sobre os sistemas de cotas na sociedade civil, há um entendimento jurisprudencial favorável à constitucionalidade das normas pelo Supremo Tribunal Federal (STF) no ano de 2012 que repercute na necessidade de se instrumentalizar as cotas por um período de tempo determinado e em conjunto com outras políticas e ações de focalização à população alvo. 


\section{REFERÊNCIAS}

BARBOSA, J. F. S. “A desigualdade inconstitucional da Lei $n^{\circ}$ 12.990/2014, que estabelece cotas raciais em concursos públicos federais". Revista Jus Navigandi, ano 19, n.4002, junho, 2014. Disponível em: <www.jus.com.br>. Acesso em 19/02/2014.

BONADIMAN, D. "A inconstitucionalidade do sistema de cotas para negros". Revista Âmbito Jurídico, ano XVI, n. 117, outubro, 2013. Disponível em: <www.ambito-juridico.com.br>. Acesso em 19/02/2014.

BRASIL. Decreto Federal n. 3.298, de 20 de dezembro de 1999. Brasília: Planalto, 2014. Disponível em: <www.planalto.gov.br>. Acesso em 19/02/2015.

BRASIL. Lei Federal, n. 7.853, de 24 de outubro de 1989. Brasília: Planalto, 2014. Disponível em: <www.planalto.gov.br>. Acesso em 19/02/2015.

BRASIL. Lei Federal 9.504, de 30 de setembro de 1997. Brasília: Planalto, 1997. Disponível em: <www.planalto.gov.br>. Acesso em 19/02/2015.

BRASIL. Lei Federal 12.288, de 20 de julho de 2010. Brasília: Planalto, 1997. Disponível em: <www.planalto.gov.br>. Acesso em 19/02/2015.

BRASIL. Lei Federal n. 12.990, de 9 de junho de 2014. Brasília: Planalto, 2014. Disponível em: <www.planalto.gov.br>. Acesso em 19/02/2015.

FRY, P. H. "Ciência social e política 'racial' no Brasil". Revista USP, n. 68, fevereiro, 2006.

FRY, P. H. "The politics of racial classification in Brazil". Journal de la Société des Américanistes, vol. 95, 2009.

GARCEZ, V. B. V. "As políticas de cotas sociais e étnico-raciais na Universidade Federal de Sergipe sob a ótica do princípio da isonomia". Cadernos de Graduação - Ciências Humanas e Sociais, vol. 1, n.16, 2013.

GLUZ, N. "Discriminação positiva". In: OLIVEIRA, D.A.; DUARTE, A.M.C.; VIEIRA, L.M.F. Dicionário: trabalho, profissão e condição docente. Belo Horizonte: UFMG, 2010.

GOMES, J. B. B. Ação afirmativa \& princípio constitucional da igualdade: o direito como instrumento de transformação social. A experiência dos EUA. Rio de Janeiro: Renovar, 2001. 
MAGGIE, Y. “Anti-Racismo Contra Leis Raciais”. Revista Interesse Nacional, vol. 1, 2008.

MAGGIE, Y. "Políticas de cotas e o vestibular da UnB ou a marca que cria sociedades divididas”. Horizontes antropológicos, vol. 11, n. 23, 2005.

MEC - Ministério da Educação. Sistema de cotas. Disponível em: Disponível em <www. portal.mec.gov.br/cotas>. Acesso em 24/03/2013.

MELlO, C. A. B. Conteúdo jurídico do princípio da igualdade. São Paulo: Malheiros Editores, 2003.

QUINTÃO, B. O. “A (in)constitucionalidade das cotas raciais em concursos públicos”. Revista Ius Gentium, vol. 10, n. 5, 2014.

ROCHA, C. L. A. “Ação afirmativa: o conteúdo democrático do princípio da igualdade jurídica”. Revista Trimestral de Direito Público, n. 15, 1996.

SENHORAS, E. M. "Cultura e Poder: Um percurso da construção dos discursos e ações sobre raça na formação nacional”. Revista Urutágua, n. 8, dezembro, 2005.

SENHORAS, E. M. "Políticas Públicas nos Anos Noventa: Um Ensaio sobre as Causas e Implicações da Crise do Estado Brasileiro de Bem-Estar Social”. Revista Oikos, vol. 2, n. 2, 2003.

SILVA, L. F. M. “Considerações sobre o tema 'políticas públicas de ação afirmativa para a população negra no Brasil’”. Revista Direito e Práxis, vol. 3, n. 2, 2011.

SILVA, T. D.; SILVA, J. M. "Reserva de vagas para negros em concursos públicos: uma análise a partir do Projeto de Lei 6.738/2013”. Nota técnica, n. 17, fevereiro, 2014. Disponível em: <www.ipea.gov.br>. Acesso em 19/02/2015.

SOUSA, L. P.; PORTES, E. A. “As propostas de políticas/ações afirmativas das universidades públicas e as políticas/ações de permanência nos ordenamentos legais". Revista Brasileira de Estudos Pedagógicos, vol. 92, n. 232, 2011.

STF - Supremo Tribunal Federal. Arguição de Descumprimento de Preceito Fundamental n. 186. Decisão final. Brasília: STF, 2012.

TRINDADE, F. A constitucionalidade da discriminação positiva. Brasília: Senado Federal, Consultoria Legislativa, 1998.

UERJ - Universidade do Estado do Rio de Janeiro. Programa Políticas da Cor na Educação Brasileira. Rio de Janeiro: UERJ, 2013. Disponível em: www.politicasdacor.net. Acesso em 23/03/2013. 